Pacific Journal of Mathematics

A REMARK ON SPINOR NORMS OF LOCAL INTEGRAL 


\title{
A REMARK ON SPINOR NORMS OF LOCAL INTEGRAL ROTATIONS I
}

\section{XU FeI}

\begin{abstract}
The spinor norms of the integral rotations on the modular quadratic forms over a local field, which could not be expressed in the convenient closed forms in [1], are expressed in a convenient closed form.
\end{abstract}

The spinor norms of integral rotations on a modular quadratic form over a local field were determined in [1], but there remained one case to solve. In the present paper, we will solve this problem. Familiarity of [1] and [2] is assumed, and we also adopt the notations of [1] and [2]. Thus, $F$ denotes a dyadic local field of characteristic $0, \mathscr{O}$ the ring of integers in $F, \mathscr{B}=\pi \mathscr{O}$ the maximal ideal of $\mathscr{O}, \mathscr{U}$ the group of units in $\mathscr{O}, \mathscr{D}(\cdot)$ the quadratic defect function, $V$ a regular quadratic space of dimension 2 over $F, L$ a unimodular lattice of determinant $d$ on $V, a$ the norm generator, $O^{+}(V)$ the group of rotations on $V$, $O^{+}(L)$ the corresponding subgroup of units of $L$, and $\theta(\cdot)$ the spinor norm function.

Write $L \cong A\left(a,-\delta a^{-1}\right)$, adapted to a basis $\{x, y\}$, where $\mathscr{D}(1+\delta)=$ $\delta \mathscr{O}$ and $-\delta a^{-1}$ belongs to $w L$. Put $\operatorname{ord}(a)=\nu, \operatorname{ord}(2)=e$, and $\mu=$ $e-\nu$. We have the following proposition.

Proposition. If $e+[\mu / 2] \geq \operatorname{ord}\left(\delta a^{-1}\right)>e$, then

$$
\theta\left(O^{+}(L)\right)=\left(1+\mathscr{B}^{\operatorname{ord}(\delta)+2 \mu-2 e-2[\mu / 2]}\right) \dot{F}^{2} \cap Q(\langle 1, d\rangle) \dot{F}^{2}
$$

where $Q(\langle 1, d\rangle)=\{a \cdot c \mid c \in Q(\dot{V})\}$.

Proof. Take any symmetry $S z$ in $O(L)$ where $z$ is a maximal anisotropic vector of $L$. Put $z=s \cdot x+t \cdot y$ where $s, t \in \mathscr{O}$ and one of them must be a unit. Since $\operatorname{ord}(Q(z))=\operatorname{ord}\left(s^{2} a+2 s t-t^{2} \cdot \delta \cdot a^{-1}\right) \leq e$, we obtain $0 \leq \operatorname{ord}(s) \leq[\mu / 2]$ and $Q(z)=s^{2} a \cdot\left(1+2 s^{-1} t a^{-1}-\left(s^{-1} t\right)^{2}\left(\delta a^{-1}\right) a^{-1}\right)$. If $s$ is a unit,

$$
\begin{aligned}
& \operatorname{ord}\left(2 s^{-1} t a^{-1}-\left(s^{-1} t\right)^{2}\left(\delta a^{-1}\right) a^{-1}\right)=\operatorname{ord}\left(2 s^{-1} t a^{-1}\right) \geq e-\nu \\
& \quad=(\operatorname{ord}(\delta)+2 \mu-2 e-2[\mu / 2])+(e+[\mu / 2]+\nu-\operatorname{ord}(\delta))+[\mu / 2] \\
& \quad \geq \operatorname{ord}(\delta)+2 \mu-2 e-2[\mu / 2] .
\end{aligned}
$$


If $t$ is a unit,

$$
\begin{aligned}
& \operatorname{ord}\left(2 s^{-1} t a^{-1}-\left(s^{-1} t\right)^{2}\left(\delta a^{-1}\right) a^{-1}\right) \\
& \quad \geq \min (\mu-\operatorname{ord}(s), \operatorname{ord}(\delta)-2 \nu-2 \operatorname{ord}(s)) .
\end{aligned}
$$

When $\operatorname{ord}(s) \geq \operatorname{ord}(\delta)+\mu-2 e$,

$$
\begin{aligned}
& \min (\mu-\operatorname{ord}(s), \operatorname{ord}(\delta)-2 \nu-2 \operatorname{ord}(s)) \\
& \quad=\operatorname{ord}(\delta)-2 \nu-2 \operatorname{ord}(s) \\
& \quad \geq \operatorname{ord}(\delta)-2 \nu-2[\mu / 2] \\
& \quad=\operatorname{ord}(\delta)+2 \mu-2 e-2[\mu / 2]
\end{aligned}
$$

When $\operatorname{ord}(s)<\operatorname{ord}(\delta)+\mu-2 e$,

$$
\begin{aligned}
\min & (\mu-\operatorname{ord}(s), \operatorname{ord}(\delta)-2 \nu-2 \operatorname{ord}(s)) \\
\quad & =\mu-\operatorname{ord}(s)>2 e-\operatorname{ord}(\delta) \\
& =(\operatorname{ord}(\delta)+2 \mu-2 e-2[\mu / 2])+2(e+[\mu / 2]+\nu-\operatorname{ord}(\delta)) \\
& \geq \operatorname{ord}(\delta)+2 \mu-2 e-2[\mu / 2] .
\end{aligned}
$$

By the theorem of [3], we obtain

$$
\theta\left(O^{+}(L)\right) \subseteq\left(1+\mathscr{B}^{\text {ord }(\delta)+2 \mu-2 e-2[\mu / 2]}\right) \dot{F}^{2} .
$$

It is obvious that $V$ is anisotropic in this case, so $\theta\left(O^{+}(V)\right)=Q<1$, $d>\dot{F}^{2}$. Hence, $\theta\left(O^{+}(L)\right) \subseteq(1+\mathscr{B}$ ord $(\delta)+2 \mu-2 e-2[\mu / 2]) \dot{F} \cap Q(\langle 1, d\rangle) \dot{F}^{2}$.

Take any $a \cdot h \dot{F}^{2} \subseteq(1+\mathscr{B}$ ord $(\delta)+2 \mu-2 e-2[\mu / 2]) \dot{F}^{2} \cap Q(\langle 1, d\rangle) \dot{F}^{2}$ where $h \in Q(\dot{V})$, so there exists $z$ in $\dot{V}$ such that $h=Q(z)$. Without loss of generality, we can assume that $z=s \cdot x+t \cdot y$ where $s, t \in \mathscr{O}$ and one of them must be a unit.

If $[\mu / 2]<\operatorname{ord}(s) \leq \mu-e+(\operatorname{ord}(\delta)-1) / 2$, then $t$ is a unit. Since

$$
\begin{aligned}
\operatorname{ord}\left(\left(s t^{\dashv}\right) \cdot\left(a \delta^{\dashv}\right) \cdot 2\right) & =\operatorname{ord}(s)-\operatorname{ord}\left(\delta a^{\dashv-}\right)+e \\
& \geq \operatorname{ord}(s)-[\mu / 2]>0
\end{aligned}
$$

we know that $\left(s \cdot t^{-1}\right) \cdot\left(a \delta^{-1}\right) \cdot 2-1$ is a unit. Let $\operatorname{ord}(s)=m$, so

$$
\begin{aligned}
a \cdot h & =a\left(s^{2} a+2 s t-t^{2}\left(\delta a^{-1}\right)\right) \\
& =(a s)^{2} \cdot\left(1+\left(s^{-1} t\right)^{2}\left(\delta a^{-1}\right) \cdot\left(a^{-1}\right) \cdot\left(\left(s t^{-1}\right) \cdot\left(a \delta^{-1}\right) \cdot 2-1\right)\right)
\end{aligned}
$$

in $\left(1+\mathscr{B}^{\operatorname{ord}(\delta)+2 \mu-2 e-2[\mu / 2])} \dot{F}^{2}\right.$. Notice

$$
\operatorname{ord}\left(\left(s^{-1} t\right)^{2}\left(\delta a^{-1}\right) \cdot\left(a^{-1}\right)\right)=-2 m+\operatorname{ord}(\delta)-2 \nu .
$$

We obtain the equation

$$
1+w \pi^{\mathrm{ord}(\delta)-2 m-2 \nu}=f^{2}\left(1+r \pi^{\mathrm{ord}(\delta)+2 \mu-2 e-2[\mu / 2]}\right)
$$


where $w \in \mathscr{U}, r \in \mathscr{O}, f \in \dot{F}$. Since

$$
\operatorname{ord}(\delta)+2 \mu-2 e-2[\mu / 2]>\operatorname{ord}(\delta)-2 \nu-2 m \geq 1 \text {, }
$$

we can assume $f=1+q \pi^{k}$ where $q \in \mathscr{U}, k \geq 1$. So the following equation is yielded from (1).

(2) $w \pi^{\operatorname{ord}(\delta)-2 \nu-2 m}-r \pi^{\mathrm{ord}(\delta)+2 \mu-2 e-2[\mu / 2]}-2 r q \pi^{\mathrm{ord}(\delta)+2 \mu-2 e-2[\mu / 2]+k}$

$$
-r q^{2} \pi^{\operatorname{ord}(\delta)+2 \mu-2 e-2[\mu / 2]+2 k}-2 q \pi^{k}=q^{2} \pi^{2 k} .
$$

Since

$$
\begin{gathered}
\operatorname{ord}(\delta)-2 \nu-2 m \leq e+[\mu / 2]+\nu-2 \nu-2[\mu / 2] \\
=e-\nu-[\mu / 2] \leq e<e+k=\operatorname{ord}\left(2 q \pi^{k}\right)
\end{gathered}
$$

and $\operatorname{ord}(\delta)-2 \nu-2 m$ is odd, consider the orders of the elements at both sides of (2), a contradiction is derived.

If $\operatorname{ord}(s) \geq \mu-e+(\operatorname{ord}(\delta)+1) / 2$, then $t$ is a unit again. Since

$$
\operatorname{ord}\left(a^{2}\left(s t^{-1}\right)^{2} \cdot \delta^{-1}\right)=2 \nu+2 \operatorname{ord}(s)-\operatorname{ord}(\delta) \geq 1
$$

and

$$
\begin{aligned}
& \operatorname{ord}\left(2\left(s t^{-1}\right) a \delta^{-1}\right)=e+\operatorname{ord}(s)+\nu-\operatorname{ord}(\delta) \\
& \quad \geq e+(1-\operatorname{ord}(\delta)) / 2 \geq e+(1-e-[\mu / 2]-\nu) / 2 \\
& \quad=(e-[\mu / 2]-\nu) / 2+1 / 2>0
\end{aligned}
$$

we know $\left(1-a^{2}\left(s t^{-1}\right)^{2} \delta^{-1}-2\left(s t^{-1}\right) a \delta^{-1}\right) \in \mathscr{U}$. Notice

$$
\begin{aligned}
a \cdot h & =a\left(s^{2} a+2 s t-t^{2}\left(\delta a^{-1}\right)\right) \\
& =\delta\left(-t^{2}\right)\left(1-a^{2}\left(s t^{-1}\right)^{2} \delta^{-1}-2\left(s t^{-1}\right) a \delta^{-1}\right)
\end{aligned}
$$

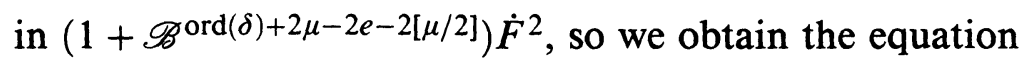

$$
\delta \cdot \eta=\zeta \cdot f^{2}
$$

where $\eta \in \mathscr{U}: f \in \dot{F}, \zeta \in(1+\mathscr{B}$ ord $(\delta)+2 \mu-2 e-2[\mu / 2]) \subseteq \mathscr{U}$. Since ord $(\delta)$ is odd, consider the orders of the elements at both sides of (3), a contradiction is derived.

Now the only possibility is $0 \leq \operatorname{ord}(s) \leq[\mu / 2]$, so

$$
\operatorname{ord}(Q(z))=\operatorname{ord}\left(s^{2} a+2 s t-t^{2}\left(\delta a^{-1}\right)\right) \leq e
$$

and $z$ is a maximal vector of $L$, thus $S z \in O(L)$, and $S x \cdot S z \in O^{+}(L)$. Notice

$$
\theta(S x \cdot S z)=a \cdot h \dot{F}^{2}
$$

hence, $\theta\left(O^{+}(L)\right)=\left(1+\mathscr{B}^{\operatorname{ord}(\delta)+2 \mu-2 e-2[\mu / 2]}\right) \dot{F}^{2} \cap Q(\langle 1, d\rangle) \dot{F}^{2}$. 
Combining the above proposition with the results obtained in [1], we conclude that the spinor norms of integral rotations on a modular quadratic form over a local field are determined completely and all the results are expressed in the conventional closed forms.

\section{REFERENCES}

[1] J. S. Hsia, Spinor norms of local integral rotations, I, Pacific J. Math., 57 (1975), 199-206.

[2] O. T. O'Meara, Introduction to Quadratic Forms, Berlin-Göttingen-Heidelberg: Springer, 1963.

[3] O. T. O'Meara and B. Pollak, Generation of local integral orthogonal groups, II, Math. Zeitschr., 93 (1966), 171-188.

Received October 6, 1987.

University of Science and Technology of China HeFeI ANHUI

People's Republic of China 


\section{PACIFIC JOURNAL OF MATHEMATICS EDITORS}

\author{
V. S. VARADARAJAN \\ (Managing Editor) \\ University of California \\ Los Angeles, CA 90024 \\ HeRbert Clemens \\ University of Utah \\ Salt Lake City, UT 84112 \\ THOMAS ENRIGHT \\ University of California, San Diego \\ La Jolla, CA 92093
}

R. FINN

Stanford University

Stanford, CA 94305

HERMANN FLASCHKA

University of Arizona

Tucson, AZ 85721

VAUGHAN F. R. JONES

University of California

Berkeley, CA 94720

STEVEN KERCKHOFF

Stanford University

Stanford, CA 94305

\section{ROBION KIRBY}

University of California

Berkeley, CA 94720

C. C. MOORE

University of California

Berkeley, CA 94720

HAROLD STARK

University of California, San Diego

La Jolla, CA 92093

\section{ASSOCIATE EDITORS}
R. ARenS
E. F. BECKENBACH
B. H. NeumanN
F. WOLF
K. YOSHIDA (1906-1982)

\section{SUPPORTING INSTITUTIONS}
UNIVERSITY OF ARIZONA
UNIVERSITY OF OREGON
UNIVERSITY OF BRITISH COLUMBIA
UNIVERSITY OF SOUTHERN CALIFORNIA
CALIFORNIA INSTITUTE OF TECHNOLOGY
STANFORD UNIVERSITY
UNIVERSITY OF CALIFORNIA
MONTANA STATE UNIVERSITY
UNIVERSITY OF HAWAII
UNIVERSITY OF NEVADA, RENO
UNIVERSITY OF TOKYO
NEW MEXICO STATE UNIVERSITY
UNIVERSITY OF UTAH
OREGON STATE UNIVERSITY
WASHINGTON STATE UNIVERSITY
UNIVERSITY OF WASHINGTON 


\section{Pacific Journal of Mathematics}

\section{Vol. 136, No. $1 \quad$ November, 1989}

Robert Archbold and Frederic W. Shultz, Characterization of $C^{*}$-algebras with continuous trace by properties of their pure states $\ldots \ldots \ldots \ldots \ldots \ldots 1$

Shu Ping Chen and Roberto Triggiani, Proof of extensions of two conjectures on structural damping for elastic systems $\ldots \ldots \ldots \ldots \ldots \ldots$

Philip Throop Church and James Timourian, A nonlinear elliptic

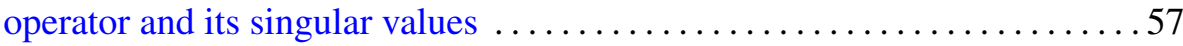

A. Gervasio Colares and Katsuei Kenmotsu, Isometric deformation of surfaces in $R^{3}$ preserving the mean curvature function $\ldots \ldots \ldots \ldots \ldots 71$

Fei Xu, A remark on spinor norms of local integral rotations. I . . . . . . . 81

Pedro Martinez Gadea and Ángel María Montesinos-Amilibia, Spaces of constant para-holomorphic sectional curvature $\ldots \ldots \ldots \ldots \ldots \ldots \ldots 5$

Guangxin Zeng, Homogeneous Stellensätze in semialgebraic geometry . . . . 103

Thomas Eric Hall, The isomorphism problem for orthodox semigroups . . . . 123

Mike Hoffman, Noncoincidence index, free group actions, and the fixed

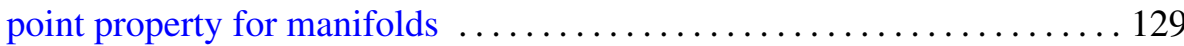

Terry Atherton Loring, The noncommutative topology of one-dimensional

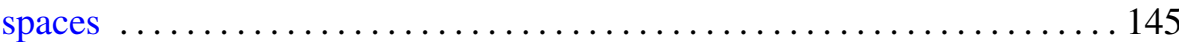

Haskell Paul Rosenthal and Alan Evan Wessel, The Krě̆ n-Mil'man property and a martingale coordinatization of certain nondentable convex sets

Yoshimi Saito, A remark on the limiting absorption principle for the reduced wave equation with two unbounded media 